\title{
Central hemodynamic response to interval aerobic jogging in healthy male students
}

\author{
Javad Mahdiabadi
}

\author{
Belarusian State University of Physical Culture, Minsk, Republic of Belarus
}

\begin{abstract}
Purpose:

Regular training improves maximal oxygen consumption (VO2max) and cardiovascular function. The aim of this study was to determine the central hemodynamic adaptation after interval aerobic jogging in healthy male students.

Material: $\quad$ Twenty untrained male students (aged 18-20 years) were volunteered and randomly divided into two groups: interval $(l ; n=10)$ and control $(C ; n=10)$. Countryside interval jogging programme $5 \times 9$ min at $70 \%$ of Maximum Heart Rate interspersed with 4 min inactive recovery, 3 days/week for 8-weeks performed. The control group remained sedentary during the period. VO2max obtained using the step-test. Standard medical method of tetrapolar chest reography (impedance cardiography) was performed for hemodynamic parameters, during resting and after workload (Step-test) conditions, before and after the training.

Results: $\quad$ Using t-test, after eight weeks the resting heart rate in both groups did not change significantly $(P>0.05)$. The stroke volume increased significantly in I group after workload $(P \leq 0.05)$. The cardiac output $(C O)$ did not change significantly in both groups $(P>0.05)$. The systolic blood pressure in I group decreased significantly at rest and after workload $(P \leq 0.05)$. The diastolic blood pressure did not change significantly in both groups $(P>0.05)$. The systemic vascular resistance in the both groups did not change significantly $(P>0.05)$. The maximal aerobic capacity absolute and relative increased significantly in I group ( $\leq 0.05)$. Significant difference between groups in stroke volume, cardiac output, VO2max absolute and relative $(P \leq 0.05)$ was found.

Conclusions: Eight weeks aerobic interval jogging can influence on central hemodynamic and VO2max in male students. Keywords: stroke volume, blood pressure, cardiac output, maximal oxygen consumption.
\end{abstract}

\section{Introduction}

Physical training, as part of cardiac rehabilitation, is effective in improving vascular function, pulmonary circulation, ventricular remodeling and functional capacity and quality of life in patients with coronary artery disease $[16,20]$. However, the benefit of training on left ventricular diastolic and systolic function is controversial $[11,39,46]$. The most cases of physiological modification are heart rate and blood pressure due to physical activity [28]. The response of the heart rate and blood pressure to exercise depends on factors like active muscle mass, type of muscle fiber, intensity and the training method [23, 29].

Measures of cardiac output (CO) help to develop the information about physiological responses and mechanisms of adaptation due to the physical training, sedentary lifestyle and chronic disease. $\mathrm{CO}$ - the product of stroke volume (SV) and heart rate (HR) - indicates the body's ability to meet the metabolic demands of training; it may increase from 5- to 6-fold during training [44]. Coordination the function of autonomic nervous system (marked with rapid and sustained parasympathetic withdrawal coupled with sympathetic activation) is required for this to happen. The increase in $\mathrm{HR}$ is responsible for the majority of the enhancement the $\mathrm{CO}$ during training, and peak HR is a basically limiting factor of peak exercise capacity in healthy person. Maximal HR does not increase with training. In contrast, with prolonged physical training increases in $\mathrm{SV}$ - both at rest and during exercise - demonstrated [4].

Studies show that during physical activity increase in

(C) Javad Mahdiabadi, 2017

doi:10.15561/18189172.2017.0404
HR is responsible for 50 to 70 percent, contractility 15 to 25 percent and ventricular work for 15 to 25 per cent of myocardial oxygen consumption is responsible [10].

Intensive Interval training is divided into two main categories: sprint and aerobic types. Sprint-type interval training improves maximal oxygen consumption $\left(\mathrm{VO}_{2 \max }\right)$ mainly through increased oxidative capacity in peripheral muscles [14]. Aerobic-type interval training improves $\mathrm{VO}_{2 \max }$ mainly through improved cardiac function [45]. The lowest intensity for improving $\mathrm{VO}_{2 \max }$ seems to be approximately 55 - 65\% of maximal heart rate [25]. Studies confirm that training programs that involve relatively high-intensity are more effective in improving $\mathrm{VO}_{2 \max }$, cardiac function than moderate intensities, in healthy individuals [18, 26, 41]. Gibala et al. [15] have shown that interval training as compared with continuous training is more efficient in inducing rapid adaptations in skeletal muscles and exercise performance. Molmen-Hansen et al. [30] demonstrated that interval training could reduce blood pressure (BP) and improve heart function of hypertensive patients. In addition, several previous studies had reported that high intensity interval training could be used in both clinical practice and experiments, and that such exercise modality had greater beneficial effects on the heart [123, 45]. However, the sub-acute effects occur immediately after finishing the training, and involve chronic physiological adaptations that develop over the training period [9]. Information about heart function during low intensity aerobic interval training is limited and more studies have investigated the effects of intensive interval training.

Tjonna et al. [40] found that aerobic interval and 
continuous training on average three times a week on a treadmill for 16 weeks reduced systolic and diastolic blood pressure in patients with metabolic syndrome. Ciolac et al. [8] observed a decrease in mean 24-h systolic and diastolic blood pressure in long-term treated hypertensive patients. Sijie T et al. [38] showed no significant change in SBP and DBP after 15-week high intensity interval training in overweight young women. Ricardo FontesCarvalho et al. [12] showed 8-weeks aerobic training after myocardial infarction did not significantly improve diastolic or systolic function parameters, although it was associated with a significant improvement in $\mathrm{VO}_{2}$

Despite much research, still cannot be said with certainty that aerobic interval training have a significant impact on the function of cardiovascular system. Therefore, in this study the effect of aerobic interval jogging on central hemodynamic parameters of heart in male students investigated.

\section{Material and methods}

Participants. The study was performed on 20 nonathletic male students of the Belarusian state University of physical culture (Belarus) aged from 18-20 years (interval training group $\mathrm{IG} ; \mathrm{n}=10$ and control group $\mathrm{CG} ; \mathrm{n}=10$ ), who took part in the study. Each participant gave informed consent before enrolment. The students did not have any sports category. The criterion for cardiovascular health was the data obtained from the questionnaire devised by the researcher. Before the initiation to participate in the study, the subjects were informed of the process and filled out the medical sport questionnaire and the consent form.

Training programme. Training programme was designed including a 45-minutes countryside interval jogging with $70 \%$ of the maximum heart rate (MHR), three times a week for eight weeks, $5 \times$ minutes with 4-minute inactive rest intervals between them. The subjects warmed up for 10 min before starting the main programme, and cooled down for 10 min after the main programme. All the training sessions were supervised by the researcher. The control group remained sedentary during the period.

Complex «Impecard-M TU RB14563250. 017-96. made in Belarus» was used to study central hemodynamics (HR, SV, CO, SVR) with application of standard medical method of tetrapolar chest reography (impedance cardiography).

Blood pressure (BP) was measured manually using mechanical aneroid sphygmomanometer and a quality stethoscope (MDF $®$ Calibra Professional Aneroid Sphygmomanometer and Stethoscope). Resting blood pressure (BP) was measured 3 times in the seated position. The average of the 3 readings was used for the representative examination value. The measurement was performed under controlled conditions in a quiet room. The cuff of the blood pressure monitor was placed around the upper right arm.

The heart beat while resting was measured by 60 -s count, maximum heart rate was determined by the formula:

$\mathrm{HR}_{\max }=220$ beats $/ \mathrm{min}-$ age.

It is a simple step-test that uses a step bench that is 40 $\mathrm{cm}$ high for males. Subjects exercise with a step frequency of 22.5 steps per minute under the metronome for 6 minutes. Aerobic capacity was expressed as estimated maximal oxygen consumption $\left(\mathrm{VO}_{2 \max }\right)$, obtained using the step-test and the Astrand-Ryhming nomogram from the steady state heart rate (HR) and workload [1].

Statistical analysis. Descriptive statistics, a t-test for paired data was used to assess differences between preand post-tests in groups and independent t-test to assess differences between groups, $\mathrm{P}$ equal to or less than 0.05 was considered as the significance level. Data normality was checked with Kolmogorov - Smirnov test.

\section{Results}

General features and demographic characteristics of the participants are summarized in Table 1. Absolute values of central hemodynamic features of the participants are summarized in Table 2. After eight weeks the resting heart rate (HR) in the interval and control groups did not change significantly $(\mathrm{P}>0.05)$. The stroke volume (SV) increased significantly in the interval group after workload $(\mathrm{P} \leq 0.05)$. The cardiac output $(\mathrm{CO})$ did not change significantly in both groups $(\mathrm{P}>0.05)$. The systolic blood pressure (SBP) in the interval group decreased significantly at rest and after workload $(\mathrm{P} \leq 0.05)$. The diastolic blood pressure did not change significantly in both groups $(\mathrm{P}>0.05)$. The systemic vascular resistance (SVR) in the interval and control groups did not change significantly $(\mathrm{P}>0.05)$. The maximal oxygen consumption absolute and relative $\left(\mathrm{VO}_{2 \max }\right.$ absolute, $\mathrm{VO}_{2 \max }$ relative) increased significantly in the interval group $(\mathrm{P} \leq 0.05)$. Significant difference were observed between groups in $\mathrm{SV}, \mathrm{CO}, \mathrm{VO}_{2 \max }$ absolute and $\mathrm{VO}_{2 \max }$ relative $(\mathrm{P} \leq 0.05)$.

\section{Discussion}

In the present study, HR decreased no significantly in the interval group after 8-weeks training in rest and after workload. Meyer et al. [26] observed increase in the HR, on the other hand, Rodrigues et al. [36] showed decrease in HR after aerobic training. SV increased in rest and workload but was significantly in workload. Aerobic

Table 1. General characteristics of the subjects

\begin{tabular}{lll}
\hline Variables & Interval training & Control group \\
\hline Age (year) & $18,5 \pm 0,5$ & $18,2 \pm 0,2$ \\
Height $(\mathrm{cm})$ & $175,9 \pm 5,1$ & $176,2 \pm 4,5$ \\
Weight $(\mathrm{kg})$ & $69,2 \pm 6,1$ & $71,8 \pm 3,84$ \\
\hline
\end{tabular}


Table 2. Absolute values of central hemodynamic features in the interval and control groups

\begin{tabular}{|c|c|c|c|c|c|}
\hline \multirow[b]{2}{*}{ Variables } & \multirow{2}{*}{$\begin{array}{l}\text { Groups } \\
\text { Status }\end{array}$} & \multicolumn{2}{|l|}{ Interval } & \multicolumn{2}{|l|}{ Control } \\
\hline & & Before training & $\begin{array}{l}\text { After 8-weeks } \\
\text { training }\end{array}$ & Before training & After 8-weeks \\
\hline $\mathrm{HR}$ & Rest & $68,2 \pm 6,5$ & $66,2 \pm 3,7$ & $71,3 \pm 7,5$ & $68,3 \pm 5,4$ \\
\hline beats. $\min ^{-1}$ & Step-test & $135,2 \pm 11,2$ & $124,0 \pm 8,5$ & $132,2 \pm 20,7$ & $127,0 \pm 24,2$ \\
\hline SV, & Rest & $81,2 \pm 19,2$ & $89,1 \pm 22,1^{* *}$ & $78,3 \pm 22,3$ & $80,5 \pm 21,7$ \\
\hline $\mathrm{ml}$ & Step-test & $70,3 \pm 18,1$ & $84,1 \pm 14,9^{*}$ & $72,4 \pm 14,3$ & $77,5 \pm 16,2$ \\
\hline $\mathrm{CO}$ & Rest & $5,6 \pm 0,7$ & $5,8 \pm 0,8$ & $5,7 \pm 1,4$ & $5,5 \pm 0,9$ \\
\hline I. $\min ^{-1}$ & Step-test & $9,3 \pm 1,8$ & $10,5 \pm 1,4$ & $9,8 \pm 1,9$ & $9,8 \pm 1,6$ \\
\hline SBP, & Rest & $128,7 \pm 6,2$ & $115,3 \pm 4,2^{*}$ & $121,6 \pm 2,8$ & $120,0 \pm 5,7$ \\
\hline $\mathrm{mmHg}$ & Step-test & $158,5 \pm 14,0$ & $140,3 \pm 5,9^{*}$ & $150,0 \pm 10,0$ & $140,0 \pm 17,3$ \\
\hline DBP, & Rest & $78,7 \pm 2,18$ & $75,0 \pm 5,0$ & $78,5 \pm 7,4$ & $76,6 \pm 2,8$ \\
\hline $\mathrm{mmHg}$ & Step-test & $76,8 \pm 8,9$ & $69,8 \pm 8,1^{* *}$ & $81,6 \pm 2,9$ & $77,1 \pm 9,5$ \\
\hline SVR, & Rest & $1056,2 \pm 109,3$ & $1007,8 \pm 107,8$ & $1107,8 \pm 114,9$ & $1061,7 \pm 120,2$ \\
\hline dynes $\cdot \mathrm{sec}^{\cdot} \mathrm{cm}^{5}$ & Step-test & $1026,8 \pm 126,1$ & $927,0 \pm 104,5$ & $1065,9 \pm 120,3$ & $1032,5 \pm 127,8$ \\
\hline $\begin{array}{l}\mathrm{VO}_{2 \max } \text { absolute, } \\
\text { I. } \min ^{-1}\end{array}$ & Step-test & $4,1 \pm 0,6$ & $4,7 \pm 0,5^{*, * *}$ & $3,6 \pm 1,1$ & $3,7 \pm 0,7$ \\
\hline 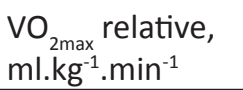 & Step-test & $52,6 \pm 8,8$ & $62,9 \pm 6,3^{*, * *}$ & $48,1 \pm 10,9$ & $51,4 \pm 11,5$ \\
\hline
\end{tabular}

Note: Significantly different than before training at statistical level: ${ }^{*}$ in groups, ${ }^{* *}$ between groups $-P \leq 0.05$

exercise for a long time can affect the parasympathetic nerve, thus increasing $\mathrm{SV}$ and reducing the resting HR $[3,5,35]$. Increase in SV due to increases in ventricular end-diastolic volume and due to reductions in endsystolic volume [31]. CO increased in rest and workload but did not significantly. Regular training is associated with central and peripheral cardiovascular adaptations that help the generation of a large and sustained cardiac output and a large stroke volume $[2,33]$. Increase in SV at workload demonstrates adaptation of cardiovascular system participants after 8 -weeks interval training and increase efficiency heart function alongside a decrease in $\mathrm{HR}$ and stronger heart contractions leads to increase CO. After 8-weeks SV interval group was significantly higher than control group.

After 8-weeks interval training SBP significantly decreased, DBP decreased no significantly in rest and workload. Kelley GA et al. [22] reported reductions in resting systolic and diastolic blood pressure $3.3 \mathrm{~mm} \mathrm{Hg}$ in normotensive, $5.4 \mathrm{~mm} \mathrm{Hg}$ in borderline hypertensive, and $10,8 \mathrm{~mm} \mathrm{Hg}$ in hypertensive individuals after aerobic training. Tjonna et al. [41] investigated that the intensity aerobic interval training reduces SBP and DBP in healthy men. Park et al. [32] showed significantly decrease in systolic blood pressure after aerobic exercise. On the other hand, some researchers noted no significant changes in blood pressure after aerobic exercise [17, 37]. After 8-weeks DBP interval group was significantly less than control group.

Mean arterial blood pressure increases in result of dynamic exercise, largely owing to an increase in systolic blood pressure, because diastolic blood pressure remains at near-resting levels. Increase in mean arterial pressure results from an increase in cardiac output and decrease in total peripheral resistance $[9,34]$. The mechanism in which exercises have effect on blood pressure is different depending on exercise intensity, time, and exercise types, but it is known that blood pressure is decreased due to decreased activity of sympathetic nervous system and decreased peripheral resistance [7]. That confirmed with decrease in SVP at rest and after workload.

After 8-weeks interval training $\mathrm{VO}_{2 \max }$ (absolute and relative) increased significantly in rest and workload. Gormley SE et al. [17] in study on sixty-one healthy young adult were randomly assigned to (moderate, vigorous, near-maximal-intensity) aerobic training groups, showed increase the $\mathrm{VO}_{2 \max }$ significantly in all exercising groups by 7.2, 4.8, and $3.4 \mathrm{ml} \cdot \mathrm{min}^{-1} \cdot \mathrm{kg}^{-1}$. Mazurek K et al. [24] reported aerobic interval training resulted in a significantly greater improvement in $\mathrm{VO}_{2 \max }$ absolute and $\mathrm{VO}_{2 \max }$ related than in continuous aerobic training in college females. Tjonna et al. [41] showed the intensive endurance training significantly improves $\mathrm{VO}_{2 \max }$ after 10 -week of training in healthy men. 
During exercise in untrained subjects oxygen consumption reach maximal values of 30-50 $\mathrm{ml} \cdot \mathrm{kg}^{-1} \cdot \mathrm{min}^{-1}$. The variability of $\mathrm{Vo}_{2 \max }$ is due to the body composition, level of training, blood volume, hemoglobin mass, stroke volume and genetic factors. With intense aerobic training, healthy men can get a $\mathrm{VO}_{2 \max }$ near 60 $\mathrm{ml} \cdot \mathrm{kg}^{-1} \cdot \mathrm{min}^{-1}$. In elite male endurance athletes, a $\mathrm{Vo}_{2}$ in the $70-85 \mathrm{ml} \cdot \mathrm{kg}^{-1} \cdot \mathrm{min}^{-1}$ range reported $[20,43]$. Previous studies indicated that aerobic interval training improves $\mathrm{VO}_{2 \max }$ by improving cardiac function [45]. Improvements in $\mathrm{VO}_{2 \max }$ in interval training resulted by the improvements in cardiac output and more specifically stroke volume [6, 19]. Trilk et al. [42] demonstrated that interval training improved cardiac function by reducing HR and increasing SV. The initial level of aerobic fitness has a significant influence on the magnitude of improvement, since sedentary individuals achieve greater positive changes compared to athletes. In our study after 8-weeks interval training $\mathrm{VO}_{2 \max }$ increased significantly alongside a reduction in HR and elevated SV. After 8-weeks $\mathrm{VO}_{2 \max }$ in interval group was significantly higher than control group.

\section{Conclusion}

The present study demonstrated that eight weeks aerobic interval jogging increases $\mathrm{VO}_{2 \max }$ and stroke volume and reduces blood pressure and systemic peripheral resistance. The author recommends comparing the effects of low-intensity and high-intensity Interval training in project to obtain more accurate results. For people with a low level of fitness, low-intensity interval training as a procedure to increase the performance of the cardiovascular system is recommended. In general, eight weeks aerobic interval jogging can cause central hemodynamics adaptation in healthy male students at rest and workload.

\section{Conflict of interests}

The author declares that there is no conflict of interests.

\section{References}

1. Andrade CH, Cianci RG, Malaguti C, Corso SD. The use of step tests for the assessment of exercise capacity in healthy subjects and in patients with chronic lung disease. $J$ Bras Pneumol, 2012; 38: 116-124.

2. Atchley AE, Douglas PS. Left ventricular hypertrophy in athletes: morphologic features and clinical correlates. Cardiol Clin, 2007; 25: 371-382. doi:10.1016/j.ccl.2007.06.009

3. Aubert AE, Beckers F, Ramaekers D. Short-term heart rate variability in young athletes. $J$ Cardiol, 2001; 37: 85-8.

4. Baggish AL. The athlete's heart. In: Ostadal B, and Dhalla NS, editors. Cardiac adaptation. Advances in Biochemistry in Health and Disease. New York: Springer Science and Business Media; 2013. p. 289-302.

5. Bo-Ae Lee, Deuk-Ja Oh. The effects of long-term aerobic exercise on cardiac structure, stroke volume of the left ventricle, and cardiac output. $J$ Exerc Rehabil, 2016; 12: 37-41. doi:10.12965/jer.150261

6. Boutcher S H. High-intensity intermittent exercise and fat loss. J. Obes, 2011, 868305. doi:10.1155/2011/868305

7. Cavalcante MA, Bombig MT, Luna Filho B, Carvalho AC, Paola AA, Póvoa R. Quality of life of hypertensive patients treated at an outpatient clinic. Arq Bras Cardiol, 2007; 89: 245-250.

8. Ciolac EG, Guimaraes GV, D'Avila VM, Bortolotto L A, Doria E L, Bocchi E A. Acute effects of continuous and interval aerobic exercise on 24-h ambulatory blood pressure in long-term treated hypertensive patients. Int J Cardiol, 2009; 133: 381-387. doi:10.1016/j.ijcard.2008.02.005

9. da Nobrega AC. The subacute effects of exercise: concept, characteristics, and clinical implications. Exerc Sport Sci Rev, 2005; 33: 84-7.

10.Duncker DJ, Bache R J. Regulation of Coronary Blood Flow During Exercise. Physiological Reviews, 2008; 88: 10091086. doi:10.1152/physrev.00045.2006

11.Fontes-Carvalho R, Sampaio F, Teixeira M, et al. The role of a structured exercise training program on cardiac structure and function after acute myocardial infarction: study protocol for a randomized controlled trial. Trials, 2015; 16: 90. doi:10.1186/s13063-015-0612-6

12.Fontes-Carvalho R, Azevedo AI, Sampaio F, Teixeira M,
Bettencourt N, Campos L, et al. The Effect of Exercise Training on Diastolic and Systolic Function After Acute Myocardial Infarction. Medicine, 2015; 94: 1-7. doi:10.1097/ md.0000000000001450

13.Gayda M, Normandin E, Meyer P, Juneau M, Haykowsky M, Nigam A. Central hemodynamic responses during acute high-intensity interval exercise and moderate continuous exercise in patients with heart failure. Appl Physiol Nutr Metab, 2012; 37: 1171-8. doi:10.1139/h2012-109

14.Gibala MJ, McGee SL. Metabolic adaptations to shortterm high-intensity interval training: a little pain for a lot of gain? Exerc Sport Sci Rev, 2008; 36: 58-63. doi:10.1097/ jes.0b013e318168ec1f

15.Gibala MJ, Little JP, van Essen M, Wilkin GP, Burgomaster KA, Safdar A, et al. Short-term sprint interval versus traditional endurance training: similar initial adaptations in human skeletal muscle and exercise performance. J Physiol, 2006; 575:901-11. doi:10.1113/jphysiol.2006.112094

16.Gielen S, Schuler G, Adams V. Cardiovascular effects of exercise training: molecular mechanisms. Circulation, 2010; 122: 1221-1238. doi:10.1161/circulationaha.110.939959

17.Gormley SE, Swain DP, High R, Spina RJ, Dowling EA, Kotipalli US, et al. Effect of intensity of aerobic training on $\mathrm{VO}_{2 \max }$. Med Sci Sports Exerc, 2008; 40: 1336-43. doi:10.1249/MSS.0b013e31816c4839

18.Hazell TJ, Macpherson RE, Gravelle BM, Lemon PW. 10 or 30-s sprint interval training bouts enhance both aerobic and anaerobic performance. Eur J Appl Physiol, 2010; 110: 153-160. doi:10.1007/s00421-010-1474-y

19.Helgerud J, Hoydal K, Wang E, Karlsen T, Berg P, Bjerkaas $\mathrm{M}$, et al. Aerobic high-intensity intervals improve $\mathrm{VO}_{2 \text { ma }}$ more than moderate training. Medicine \& Science in Sports and Exercise, 2007; 39: 665-671. doi:10.1249/ mss.0b013e3180304570

20.Heran BS, Chen JM, Ebrahim S, et al. Exercise-based cardiac rehabilitation for coronary heart disease. Cochrane Database Syst Rev, 2011; 7: CD001800. doi:10.1002/14651858. CD001800

21.Joyner MJ, Casey DP. Regulation of Increased Blood Flow (Hyperemia) to Muscles During Exercise: A Hierarchy of Competing Physiological Needs. Physiological Reviews, 2015; 95: 549-601. doi:10.1152/physrev.00035.2013 
22.Kelley GA, Kelley KA, Tran ZV. Aerobic Exercise and Resting Blood Pressure: A Meta-Analytic Review of Randomized, Controlled Trials. Preventive cardiology, 2001;4:73-80.

23.Leicht AS, Sinclair WH, Spinks WL. Effect of exercise mode on heart rate variability during steady state exercise. Eur $J$ Appl Physiol, 2008; 102: 195-204. doi:10.1007/s00421-0070574-9

24.Mazurek K, Krawczyk K, Zmijewski P, Norkowski $\mathrm{H}$, Czajkowska A. Effects of aerobic interval training versus continuous moderate exercise programme on aerobic and anaerobic capacity, somatic features and blood lipid profile in collegate females. Annals of Agricultural and Environmental Medicine, 2014; 21: 844-849. doi: $10.5604 / 12321966.1129949$

25.McArdle W, Katch F, Katch V, editors. Exercise Physiology, Nutrition, Energy and Human Performance. Baltimore: Lippincott Williams \& Wilkins; 2010.

26. Metcalfe RS, Babraj JA, Fawkner SG, Vollaard NB. Towards the minimal amount of exercise for improving metabolic health: beneficial effects of reducedexertion high-intensity interval training. Eur J Appl Physiol, 2012; 112: 2767-2775. doi:10.1007/s00421-011-2254-Z

27.Meyer K, Foster C, Georgakopoulos N, Hajric R, Westbrook $\mathrm{S}$, Ellestad A, et al. Comparison of left ventricular function during interval versus steady-state exercise training in patients with chronic congestive heart failure. Am J Cardiol, 1998; 82: 1382-7. doi:10.1016/S0002-9149(98)00646-8

28.Mihl C, Dassen WR, Kuipers H. Cardiac remodeling: concentric versus eccentric hypertrophy in strength and endurance athletes. Neth Heart J, 2008; 16: 129-133. doi:10.1007/bf03086131

29. Mitchell JH, Payne FC, Saltin B, Schibye B. The role of muscle mass in the cardiovascular response to static contractions. J Physiol, 1980; 309: 45-54.

30.Molmen-Hansen HE, Stolen T, Tjonna AE, Aamot IL, Ekeberg IS, Tyldum GA, et al. Aerobic interval training reduces blood pressure and improves myocardial function in hypertensive patients. Eur J Prev Cardiol, 2012; 19: 151-60. doi: $10.1177 / 1741826711400512$

31.Oakley D. The athlete's heart. Heart - BMJ Journals, 2001; 86: 722-726. doi:10.1136/heart.86.6.722

32.Park SK, Park JH, Kwon YC, Yoon MS, Kim CS. The effect of long-term aerobic exercise on maximal oxygen consumption, left ventricular function and serum lipids in elderly women. J Physiol Anthropol Appl Human Sci, 2003; 22: 11-17. doi:10.2114/jpa.22.11

33.Rawlins J, Bhan A, Sharma S. Left ventricular hypertrophy in athletes. Eur $J$ Echocardiogr, 2009; 10: 350-356. doi:10.1093/ejechocard/jep017

34.Ridker PM. On evolutionary biology, inflammation, infection, and the causes of atherosclerosis. Circulation, 2002; 105: 2-4.
35.Riebe D, Franklin BA, Thompson PD, Garber CE, Whitfield GP, Magal M, et al. Updating ACSM's recommendations for exercise preparticipation health screening. Med Sci Sports Exerc, 2015; 47: 2473-2479. doi:10.1249/ MSS.0000000000000664

36.Rodrigues ACT, de Melo Costa J, Alves GB, Ferreira da Silva $\mathrm{D}$, Picard $\mathrm{MH}$, Andrade JL, et al. Left ventricular function after exercise training in young men. Am J Cardiol, 2006; 97 : 1089-92. doi:10.1016/j.amjcard.2005.10.055

37. Shiotani H, Umegaki Y, Tanaka M, Kimura M, Ando H. Effects of aerobic exercise on the circadian rhythm of heart rate and blood pressure. Chronobiol Int, 2009; 26: 1636-46. doi:10.3109/07420520903553443

38.Sijie T, Hainai Y, Fengying Y, Jianxiong W. High intensity interval training in overweight young women. $J$ Sports Med Phys fitness, 2012; 52: 255-6.

39. Smart N, Haluska B, Jeffriess L, Marwick TH. Exercise training in systolic and diastolic dysfunction: effects on cardiac function, functional capacity, and quality of life. Am Heart J, 2007; 153: 530-536. doi:10.1016/j.ahj.2007.01.004

40.Tjonna AE, Lee SJ, Rognmo O, Stølen TO, Bye A, Haram $\mathrm{PM}$, et al. Aerobic interval training versus continuous moderate exercise as a treatment for the metabolic syndrome. Circulation, 2008; 118: 346-354. doi:10.1161/ circulationaha.108.772822

41.Tjonna AE, Leinan IM, Bartnes AT, Jenssen BM, Gibala $\mathrm{MJ}$, et al. Low- and High-Volume of Intensive Endurance Training Significantly Improves Maximal Oxygen Uptake after 10-Weeks of Training in Healthy Men. PLOS ONE, 2013 8(5): e65382. doi:10.1371/journal.pone.0065382

42.Trilk JL, Singhal A, Bigelman KA, Cureton KJ. Effect of sprint interval training on circulatory function during exercise in sedentary, overweight/obese women. European journal of applied physiology, 2011; 111: 1591-7. doi:10.1007/s00421010-1777-z

43. Walker R, Hill K. Modeling growth and senescence in physical performance among the ache of eastern Paraguay. Am J Hum Biol, 2003; 15: 196-208. doi:10.1002/ajhb.10135

44. Warburton DE, Gledhill N, Jamnik VK, Krip B, Card N. Induced hypervolemia, cardiac function, VO2max, and performance of elite cyclists. Med Sci Sports Exerc, 1999; 31: 800-808.

45.Wisloff U, Ellingsen O, Kemi OJ. High-intensity interval training to maximize cardiac benefits of exercise training? Exerc Sport Sci Rev. 2009; 37: 139-46. doi:10.1097/ jes.0b013e3181aa65fc

46.Yu CM, Li LS, Lam MF, et al. Effect of a cardiac rehabilitation program on left ventricular diastolic function and its relationship to exercise capacity in patients with coronary heart disease: experience from a randomized, controlled study. Am Heart J, 2004; 147: e24. doi:10.1016/j. ahj.2003.12.004 
Javad Mahdiabadi; http://orcid.org/0000-0002-2442-3206; j_mahdiabadi@yahoo.com; Ph.D student of Exercise Physiology, Belarusian State University of Physical Culture; Pobediteley Ave., 105, Minsk, 220020, Republic of Belarus

Cite this article as: Javad Mahdiabadi. Central hemodynamic response to interval aerobic jogging in healthy male students. Pedagogics, psychology, medical-biological problems of physical training and sports, 2017;21(4):169-174. doi: $10.15561 / 18189172.2017 .0404$

The electronic version of this article is the complete one and can be found online at: http://www.sportpedagogy.org.ua/index.php/PPS/issue/archive

This is an Open Access article distributed under the terms of the Creative Commons Attribution License, which permits unrestricted use, distribution, and reproduction in any medium, provided the original work is properly cited (http://creativecommons.org/licenses/by/4.0/deed.en).

Received: 28.05 .2017

Accepted: 12.06.2017; Published: 30.08.2017 